\title{
Using non-negative matrix factorization in the "unmixing" of diffuse reflectance spectra
}

\author{
D. Heslop ${ }^{\mathrm{a}, \mathrm{b}, *}, \mathrm{~T}$. von Dobeneck ${ }^{\mathrm{a}, \mathrm{b}}, \mathrm{M}$. Höcker ${ }^{\mathrm{a}}$ \\ ${ }^{a}$ Universität Bremen, FB Geowissenschaften, Postfach 330440, 28334 Bremen, Germany \\ ${ }^{\mathrm{b}}$ Research Center Ocean Margins, University of Bremen, 28334 Bremen, Germany
}

Received 14 July 2006; received in revised form 25 January 2007; accepted 4 March 2007

\begin{abstract}
Diffuse reflectance spectrophotometry (DRS), often termed simply color scanning, is a technique applied commonly to marine sediments to provide records of compositional variations. Measured DRS spectra, however, represent the bulk response of a sediment's constituents and are therefore difficult to interpret in their raw form. A quantification technique will be proposed and discussed which approaches the analysis of DRS data sets as a linear mixing problem and applies a non-negative matrix factorization (NMF) algorithm in their decomposition. The presented methodology allows the spectra of the end-member sediment constituents and their fractional abundances to be determined using only the measured data set. Unlike other DRS data processing techniques, NMF only allows additive combinations of end-members to explain the data set and will therefore return only positive abundances. Analysis of sediments from the eastern Mediterranean Sea demonstrates the applicability of the NMF approach and the new method of Orbital Cycle Stacking establishes that the "unmixed" data is consistent with expected environmental change. (C) 2007 Elsevier B.V. All rights reserved.
\end{abstract}

Keywords: spectrophotometry; non-negative matrix factorization; Mediterranean

\section{Introduction}

For many years the visual evaluation of color, for example by comparison to Munsell charts, has played an important role in the classification of geological materials. Whilst the value of such descriptions is not questioned it is clear that assigned color classifications are subjective in nature and will vary between investigators. A more objective approach is provided by diffuse reflectance spectrophotometry (DRS), which measures the ratio of

\footnotetext{
* Corresponding author. Research Center Ocean Margins, University of Bremen, 28334 Bremen, Germany. Fax: +49 4212187008.

E-mail address: dheslop@uni-bremen.de (D. Heslop).
}

incident to reflected light intensity as a function of wavelength. DRS spanning various wavelength bands has been employed to define the spectral reflectance of a variety of geological materials. One particular advantage of the method is the rapid measurement time of most DRS instruments, which makes it possible to study very large sample sets.

Basic DRS data is a useful correlation tool, sample brightness, defined as the mean reflectance across all wavelengths, or the reflectance percentage in a single wavelength channel can provide a log of changing sediment lithology that can be correlated to climatic change (Peterson et al., 2000; Lourens et al., 2001). Whilst such an approach is useful for correlations, DRS data has also been used in a more detailed manner, 
attempting to identify and quantify the individual constituents that contribute to reflectance spectra.

Grayscale, brightness and $L^{*}$, which are all measures of optical lightness that can be derived from DRS data, were studied in detail by Balsam et al. (1999) as plausible methods to assess carbonate abundance in marine sediments. It was found that whilst optical lightness could provide a proxy for change in relative carbonate abundance, the non-carbonate fraction of the sediment matrix also had an important influence on the measured parameters. Therefore any transfer functions relating optical brightness to carbonate abundance must be specific to a given sediment.

Using mineralogical information obtained from a subset of samples it is possible to calibrate large reflectance data sets and thus obtain more detailed compositional information. The aim of such calibration procedures in the study of marine sediments is to produce transfer functions that can yield DRS based quantitative estimates of composition and lithology. Such an approach was employed in the eastern tropical Pacific Ocean, ODP Site 846, to quantify biogenic calcite, biogenic opal and non-biogenic sedimentary components (Mix et al., 1995). Multiple regression transfer functions relating reflectance data to the mineralogy of a 200 sample calibration data set allowed downhole percentage abundances to be estimated for ODP Site 846. Similar calibration approaches have been applied to sediments from the Feni Drift in the North Atlantic to reconstruct percentage carbonate content and infer information on clay components and organic carbon (Ortiz et al., 1999a,b).

Iron bearing minerals such as hematite and goethite are easily identified by the first derivative curves of their reflectance spectra (Deaton and Balsam, 1991) and have been used as tracers for specific geological processes. In one of the first studies to use DRS with reference to specific minerals, Barranco et al. (1989) showed that hematite has a single first derivative peak centered at $575 \pm 10 \mathrm{~nm}$, the magnitude of which is concentration dependent. The authors could thus use first derivative peak height to trace the hematite of material eroded from Permo-Carboniferous red beds in order to map the transport path of the late Pleistocene/early Holocene Western Boundary Undercurrent off eastern North America.

In their identification of Atlantic sediment components (carbonate, chlorite, hematite, goethite, organic matter and smectite), Balsam and Deaton (1991) demonstrated the ability of DRS to unravel mixtures of materials. Analyzing sediments in the visible light wavelength range, Deaton and Balsam (1991) showed that it was possible to detect hematite and goethite in concentrations as low as $0.01 \%$ by weight, although this limit was found to be a function of the other materials present in the sediment matrix.

The strong reflectance of hematite and goethite allowed Balsam et al. (1995) to trace the transport of North African aeolian dust into the tropical Atlantic ocean. To quantify the aeolian dust across the study region, Balsam et al. (1995) employed the multivariate technique of factor analysis, which was performed on the first derivatives curves of the DRS data set. The first derivative curves were chosen in preference to the percentage reflectance spectra because they were thought to be easier to interpret in terms of mineral content. This approach had previously been adopted by Balsam and Deaton (1991) and allowed the entire DRS data set to be decomposed into representations of endmember spectra and their abundances. This method is now the standard approach to quantify DRS data sets and has been applied in a number of different regions, including the Argentine Basin (Balsam and Wolhart, 1993), the tropical Atlantic (Balsam et al., 1995), the Amazon Fan (Balsam et al., 1997), the Blake Ridge (Balsam and Damuth, 2000), the western North Atlantic drifts (Giosan et al., 2002) and the Gulf of Mexico (Balsam and Beeson, 2003). Whilst factor analysis does provide useful information on end-member spectra and their abundances, it does have a number of drawbacks and the limitations of factor analysis as a tool in the interpretation of DRS data will be discussed in detail in the following sections. The aim of this study is to introduce a new method for "unmixing" DRS spectra that overcomes the limitations of factor analysis and provides deeper insights into studied data sets.

\section{DRS data sets as linear mixtures}

The numerous studies which have employed factor analysis of DRS measurements to identify and quantify mineral components have assumed that the measured data can be represented by a linear mixture of a number of invariant constituent spectra, which will be referred to as end-members. For a model consisting of $m$ constituents, the end-member spectra can be held in a matrix $\mathbf{S}$ with each row of the matrix representing an individual spectrum and $l$ columns spanning the measured wavelengths. The matrix A represents abundances with $n$ rows, one for each measured DRS spectrum and a column for each end-member. If $\mathbf{A}$ is interpreted in terms of abundances then it must be assumed that all of its values are non-negative, i.e. $\mathbf{A} \geq 0$. Given an assumption of error-free perfectly linear mixing, the 
DRS data matrix $\mathbf{X}$ is composed of a row for each spectrum and can be described by:

$\mathbf{X}=\mathbf{A S}$.

In practice the observed DRS data matrix will deviate from $\mathbf{X}$ due to measurement error and possible subordinate non-linear effects (described below). Therefore, $\mathbf{X}$ will be composed of the spectral values explained by a linear model $\mathbf{A S}$ and an error kernel, $\boldsymbol{\epsilon}$ :

$\mathbf{X}=\mathbf{A S}+\boldsymbol{\epsilon}$.

Thus the primary aim is to solve the inverse "unmixing" problem using $\mathbf{X}$ to find the unknowns $\mathbf{A}$, $\mathbf{S}$ and $\boldsymbol{\epsilon}$.

Experimental investigations have shown that linear mixing is not a fully adequate model to describe DRS data. The location of the primary first derivative peaks of both hematite and goethite are known to shift to longer wavelengths with increasing concentration (Barranco et al., 1989; Deaton and Balsam, 1991) and under such circumstances $\mathbf{S}$ could not be considered as invariant. Additionally, Deaton and Balsam (1991) showed that as goethite abundance increases the height of the primary and secondary first derivative peaks increase at different rates, indicating a non-linear effect and the height of the hematite first derivative peak was shown by Barranco et al. (1989) to be a non-linear function of hematite concentration. The mineral abundances, A, expressed by DRS data can therefore not be considered as linear measures of concentration.

The combined abundances of the various components contributing to any given spectrum must sum to a total of one (Keshava et al., 2000; Keshava and Mustard, 2002), this means that in mathematical terms reflectance data are fundamentally "closed" arrays with a full additivity condition. Therefore when discussing percentage reflectance spectra fractional abundances will be employed, which follow a sum-to-one constraint and as such represent relative contributions. It is important to remember, however, that fractional abundances do not represent the mass composition of a material but instead provide information concerning the various contributions to the reflectance of the bulk sample.

Whilst it is apparent that the assumption of a linear mixing model is not strictly appropriate for the analysis of DRS data, previous experimental work has demonstrated that the non-linear effects are within acceptable limits. A large number of studies have produced successful interpretations of DRS spectra using linear models (Balsam and Deaton, 1991; Balsam and Wolhart, 1993; Balsam et al., 1995; Balsam and Deaton,
1996; Balsam et al., 1997; Balsam and Damuth, 2000; Giosan et al., 2002; Balsam and Beeson, 2003; Jin et al., 2003) and a linear unmixing model will also be adopted here. In cases where non-linear effects are significant the error kernel will have an increased magnitude or alternatively more end-member components would have to be included in order to compensate for the non-linear behaviour.

\section{Linear "unmixing" of DRS data using factor analysis}

Factor analysis of sediment reflectance data is generally performed on first derivative data sets rather than percentage reflectance spectra. Factor loadings show the spectral expression of each factor as a function of wavelength and provide information on the form of the end-member spectra. The factors may be either orthogonal or oblique within the coordinate space of the data depending on the specific type of rotation performed in the analysis. Previous studies employing factor analysis in the study of DRS data have employed either Equamax (Balsam et al., 1995) or Varimax (Balsam et al., 1997; Balsam and Damuth, 2000; Giosan et al., 2002; Balsam and Beeson, 2003; Damuth and Balsam, 2003) rotations, both of which produce orthogonal factors. For this reason only orthogonal factor analysis will be considered in the following discussion.

The factor scores show the importance of an individual factor in the first derivative spectrum of a given sample, therefore the score values are employed to represent the abundances. The scores, loadings and error terms are estimated from the measured data and the number of factors to be included in the model is normally determined with respect to the explained variance and the interpretability of the factors in a lithological context.

While factor analysis provides a simple and rapid method for decomposing first derivative reflectance data sets into end-member spectra and abundances, it also has a number of limitations. The types of factor analysis previously applied to DRS data assume that the recovered factors are orthogonal in the $l-1$ dimensional space of the derivative data, where $l$ is the number of measured wavelengths in each percentage reflectance spectrum. The assumption of orthogonality implies that no linear correlation can exist between the different factors in the model (Davis, 1986). DRS data is however fundamentally closed and as such mutual correlations must exist between different components. For such a closed system, regardless of the geological processes at work, the abundance of one end-member will automatically affect the abundances of the other end-members. Under such conditions the 
abundances of the various end-members will not be independent and correlations can exist between them.

For a quantitative analysis of DRS data sets it is necessary to determine abundances of the identified end-members. To be physically meaningful the abundances must be non-negative, i.e. $\geq 0$ and so that they account for the full composition the abundances for any measured spectrum must total 1 following the sum-to-one constraint discussed earlier (Keshava et al., 2000; Keshava and Mustard, 2002; Du et al., 2005). The factor scores that are employed to provide this estimate, can however take both positive and negative values.

The occurrence of negative values is a product of the factor analysis technique and can have two possible causes. The most fundamental and problematic origin of negative values is due to the assumption of factor analysis that the data set can be described by not only additive but also subtractive combinations of the endmembers (Davis, 1986). Negative factor scores can therefore be equivalent to negative abundances which are incompatible with a compositional model. This acts as a severe limitation on the applicability of factor analysis to processing of DRS data because it is clear that the system should only allow additive combinations originating from non-negative abundances to describe the measured spectra. The second source of negative values is more trivial, factor analysis algorithms routinely standardize the calculated distribution of scores to have a mean equal to zero and a standard deviation of one. Under such a rescaling it is possible for positive scores to become negative and vice versa, meaning information concerning both the additive and subtractive combinations required to explain the measured data are lost.

Not only do negative values provide some conceptual difficulties when thinking in terms of abundances, but they also remove the opportunity to examine how different factors may covary through a sequence of samples. In many situations it is desirable to take the ratio between the abundances of mixture components, however, in the case of factor scores this may result in a negative ratio which has no physical meaning. Additional problems will occur when the factor scores acting as the denominator variable cross zero and form a singularity, i.e. the ratio value goes to infinity.

To overcome the discussed problems it is necessary to employ an inverse modelling technique which allows the possibility of mutual correlation between endmember abundances, relies only on additive combinations to describe the measured data and can meet the sum-to-one constraint required for closed arrays.

\section{Linear "unmixing" of DRS data using non-negative matrix factorization}

The key to obtaining more meaningful end-member abundances is to factorize the matrix $\mathbf{X}$ in Eq. (2), in such a way that only non-negative values are returned for $\mathbf{A}$ and $\mathbf{S}$. The first step in determining $\mathbf{A}$ and $\mathbf{S}$ is to define a cost function that provides a measure of the difference between the data $\mathbf{X}$ and the model matrix $\hat{\mathbf{X}}$ resulting from the factorization. Here, the squared Euclidean distance is adopted:

$\|\mathbf{X}-\hat{\mathbf{X}}\|^{2}=\sum_{i j}\left(\mathbf{X}_{i j}-\hat{\mathbf{X}}_{i j}\right)^{2}$.

It is clear that the lower limit of the squared Euclidean distance is zero and the value will only vanish if $\mathbf{X}=\hat{\mathbf{X}}$ Using the squared Euclidean distance as a cost function is optimal for systems that are thought to contain Gaussian distributed errors (Lee and Seung, 2001).

To test the appropriateness of the squared Euclidean distance as a cost function for DRS data modelling the spectrum of a synthetic hematite sample was measured a total of 25 times using a Minolta CM-2002 instrument. A mean spectrum was determined for the sample, Fig. 1(a), and the residuals between the mean spectrum and the measured spectra were calculated to provide a representation of $\epsilon$. The distribution of error terms shown in Fig. 1 (b) appears to follow a Gaussian distribution and thus the squared Euclidean distance is deemed to be an appropriate cost function. The use of such a cost function is also consistent with previous studies that employed factor analysis or multiple regression, both of which are based on Euclidean distances and an assumption of Gaussian distributed errors.

Matrix decomposition under a constraint of nonnegativity was addressed by Lee and Seung (1999), who developed an iterative method of non-negative matrix factorization (NMF). In order to minimize $\|\mathbf{X}-\hat{\mathbf{X}}\|^{2}$ with respect to $\mathbf{A}$ and $\mathbf{S}$, subject to the constraint $\mathbf{A}, \mathbf{S} \geq 0$, Lee and Seung (2001) developed the following multiplicative update rule:

$S_{a \mu} \leftarrow S_{a \mu} \frac{\left(\mathbf{A}^{T} \mathbf{X}\right)_{a \mu}}{\left(\mathbf{A}^{T} \mathbf{A} \mathbf{S}\right)_{a \mu}}$

$A_{i a} \leftarrow A_{i a} \frac{\left(\mathbf{X S}^{T}\right)_{i a}}{\left(\mathbf{A S S}^{T}\right)_{i a}}$

where $i, a, \mu$ are the indices for the matrices, $\mathbf{A}$ and $\mathbf{S}$, as $i=1, \ldots, n, a=1, \ldots, m$ and $\mu=1, \ldots, l$. Lee and Seung (2001) proved that such an update approach would 

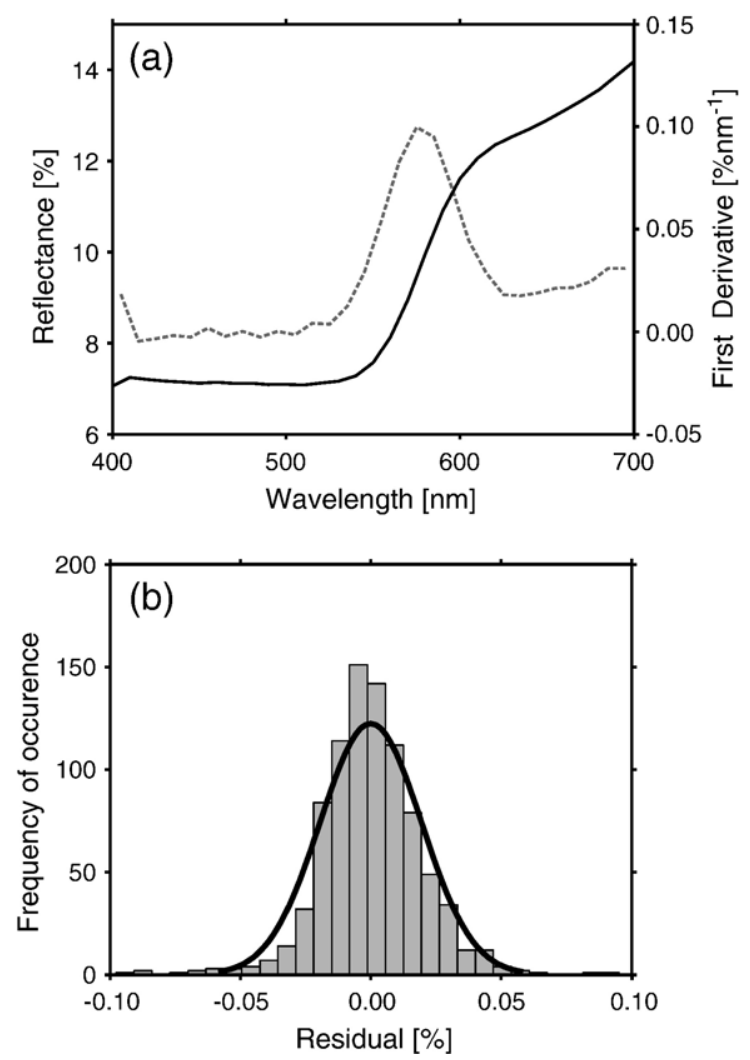

Fig. 1. (a) The mean DRS spectrum (black line) and first derivative curve (gray dashed line) were calculated for hematite after 25 repeat measurements of the same synthetic sample. The differences between the individual measured spectra and the mean percentage reflectance curve were then taken to represent typical error terms. (b) When pooled across all wavelengths the error terms describe an approximately Gaussian distribution.

converge to at least a local minimum of $\|\mathbf{X}-\hat{\mathbf{X}}\|^{2}$. Because decomposition using the NMF approach does not allow negative entries in either $\mathbf{A}$ or $\mathbf{S}$, the measured data are described only by additive combinations of the end-members. Additionally, there is no orthogonality constraint so mutual correlations can exist between the columns of A. Thus, the factorization is constrained only by $\mathbf{A}, \mathbf{S} \geq 0$. The constraint upon $\mathbf{S}$ does however mean that NMF cannot be applied directly to DRS first derivative spectra because they can contain both positive and negative values. NMF must therefore be applied to percentage reflectance spectra if $\mathbf{S} \geq 0$ is to hold. The use of percentage reflectance spectra has a number of advantages when attempting to reconstruct the composition of a mixed spectrum. Most importantly materials with flatter spectra will be almost invisible in first derivative data because their gradients are close to zero. Such an effect means that the relative importance of a given material in a first derivative spectrum depends not only its abundance but also its shape. The signal-tonoise ratio is higher for percentage reflectance spectra because taking the gradient of the data acts as a highpass filter. A further advantage of working with the percentage reflectance spectra is that the reflectance values of the end-member spectra have the same units as the measured data.

In order for the NMF algorithm to meet the sum-to-one constraint required to produce fractional abundances it is necessary to append an extra column of ones to the right hand side of both $\mathbf{X}$ and $\mathbf{S}$ before iteration of the multiplicative updates begins. After each application of the update rules the modified final column of $\mathbf{S}$ is replaced with a new column of ones, thus it does not take part in the adaption of $\mathbf{S}$ as the algorithm iterates (Du et al., 2005).

When initiating the algorithm it is necessary to provide a first estimation of both $\mathbf{A}$ and $\mathbf{S}$. Lee and Seung (2001) suggest that random numbers can be used as the simplest form of initialization, however a more structured estimate should produce a robust result when the model reaches convergence (Wild et al., 2003; Langville et al., 2006). We follow previous studies and employ fuzzy C-means cluster analysis as an initialization strategy (Weltje, 1997; Wild et al., 2003). The locations of the cluster centers of $\mathbf{X}$ provide the initial estimate of $\mathbf{S}$ and the membership of individual points to a given cluster act as starting values of the fractional abundances in $\mathbf{A}$.

\subsection{Numerical experiments}

In order to test the applicability of the NMF approach to unmixing DRS spectra a simple numerical test was performed. Reflectance spectra spanning the visible wavelength range were obtained from the ASTER Spectral Library (http://speclib.jpl.nasa.gov) for samples of hematite (sample O-1A), goethite (sample $\mathrm{OH}$ 2A), chlorite (sample PS-12C) and calcite (sample C$3 \mathrm{~A})$. These spectra were employed as end-members and were mixed together linearly using factional abundances produced using random numbers that were constrained to total 1 for each spectrum. To produce a data set similar in size to many existing DRS sediment records a total of 1000 spectra were calculated. Finally, a white noise component was added to the data using random numbers drawn from a Gaussian distribution with a mean of zero and a standard deviation corresponding to a reflectance of $0.1 \%$.

The NMF algorithm performed well in unmixing the data and recovered accurately both the end-member spectra and their fractional abundances. In order to show more detail the calculated end-member spectra are 
compared to the input end-members in terms of their first derivative curves, Fig. 2. It is apparent that the NMF algorithm recovered the end-members almost exactly, one slight exception is the calcite curve where there are small discrepancies between the true and modelled curves. The factional abundances recovered by the NMF algorithm follow the input abundances closely demonstrating the ability of the method to produce an accurate quantitative model, Fig. 3 . The data are scattered more at low values due to the proportionally larger effect of the noise contribution on small fractional abundances.

\subsection{Selecting an appropriate number of end-members}

A situation common to many unmixing problems is the decision of how many end-members should be included in the modelling procedure. A vast body of work exists concerned with the general ideas of model selection criteria (Burnham and Anderson, 2002). In recent years a number of simple approaches have been proposed to determine the optimum number of end- members to be included in a linear inverse model. Such methods have been applied successfully in sedimentology where unmixing is used to identify end-member grain size distributions and how their abundances vary on either a temporal or spatial level (Stuut et al., 2002; Holz et al., 2004).

The principle of the selection criterion involves the calculation of the coefficient of determination $\left(r^{2}\right)$ between the measured and modelled data at each wavelength. It is then possible to consider how well a given model explains the data variance across the wavelength range of the measurements. For the case of a model with insufficient end-members the variance of the input data cannot be reproduced by the model and the calculated $r^{2}$ values will be low at a number of the wavelengths. For the optimum model the $r^{2}$ value will be high across all the wavelengths and it will be found that the inclusion of additional end-members will have little effect in improving the correlation between the measured and modelled data. This approach was tested using the 4 end-member data discussed in the previous section. The coefficient of determination across all
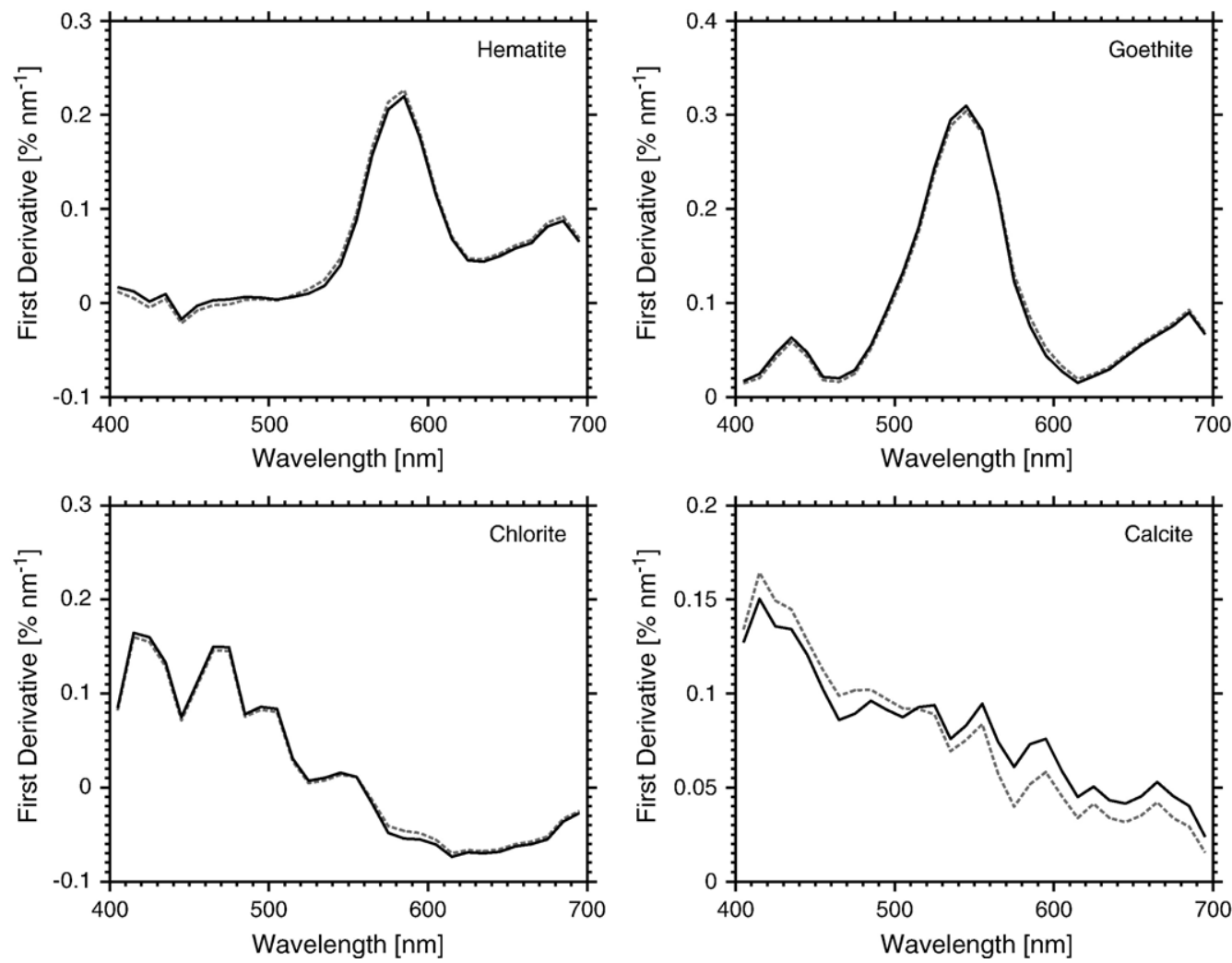

Fig. 2. NMF unmixing of the 1000 spectra data set produced during the numerical experiment yielded end-member spectra (black lines) that compare well with the known input spectra (gray dashed lines). For illustrative purposes the end-member and input spectra are compared in terms of their first derivative curves, however, the calculation to obtain the end-members was performed on the percentage reflectance data. 


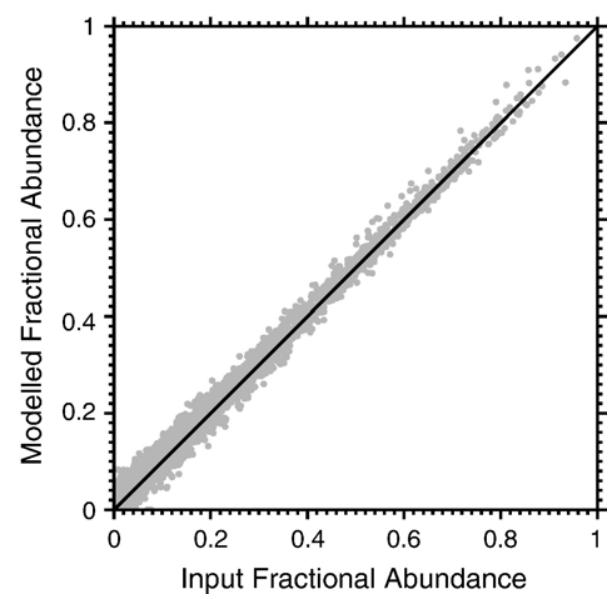

Fig. 3. The robustness of the NMF unmixing is also demonstrated by the fractional abundances obtained from the numerical experiment data set. The distribution of input fractional abundance versus modelled fractional abundance follows closely a line of unity. Scatter in the recovered abundances increases towards lower values due to the larger effect of the artificially introduced noise component.

wavelengths was calculated for 3, 4 and 5 end-member models, Fig. 4. Considering $r^{2}$ with respect to specific wavelengths, it is apparent that for certain wavelengths the 3 end-member model is not sufficiently complex to describe the data. A 4 end-member solution, however, has a value just below 1 across all wavelengths and the addition of an extra end-member produces only a slight improvement in the quality of the data fit. The presented numerical experiment demonstrates the suitability of using the coefficient of determination calculated for each wavelength in the selection of a model with an appropriate number of end-members.

\section{A Mediterranean test case: ODP Site 967}

To demonstrate the application of the NMF algorithm to the problem of unmixing reflectance data, DRS measurements from Mediterranean ODP Site 967 (34 $\left.04^{\prime} \mathrm{N}, 32^{\circ} 43^{\prime} \mathrm{E}\right)$ were analyzed. ODP Hole 967A was drilled near to the Eratosthenes Seamount in the Levantine Basin at a water depth of $2554 \mathrm{~m}$ and yielded $131 \mathrm{~m}$ of sediments. A pattern of intercalated sapropels and marls, linked to precessional changes in the Earth's orbital geometry, is common throughout the sediments of the Mediterranean (Lourens et al., 1996). During humid climatic periods (insolation maxima), Saharan aeolian flux to the Mediterranean was reduced because of increased vegetation cover in northern Africa, whilst increased productivity resulted in the formation of organic rich sapropel layers. During drier conditions (insolation minima) the reverse situation occurred with the formation of marls containing Saharan aeolian material transported by the dust storms of the rainy season (Lourens et al., 2001; Larrasoana et al., 2003). Sediment trap data from the eastern Mediterranean reveals that the modern detrital flux is dominated by desert dust thought to originate from the Sahara. In addition the average Ti/Al of the collected sediment trap samples indicates an aeolian rather than fluvial origin for the detrital material currently entering the Mediterranean (Rutten et al., 2000).

The sediments recovered from ODP 967A were composed of bioturbated nannofossil oozes, nannofossil clays and sapropels, which could be constrained within an astronomical chronology (Emeis and Sakamoto, 1998; Sakamoto et al., 1998; Kroon et al., 1998) based on the timescale of Lourens et al. (1996). Previous investigations of ODP 967A have provided geochemical (Wehausen and Brumsack, 1998; Lourens et al., 2001) and rock magnetic (Larrasoana et al., 2003) evidence for aeolian dust input, originating from Northern Africa.

Spectrophotometry measurements from the ODP 967A sediments spanning the period 0-3 Ma were analyzed. A collection of 4196 spectra from the upper $\sim 90 \mathrm{~m}$ of Hole $967 \mathrm{~A}$ were investigated with both factor analysis performed on the first derivative curves (using the software package STATISTICA 6.1 employing a Varimax rotation as recommended by Balsam and Beeson (2003) and NMF performed on the percentage reflectance spectra, using the discussed cluster analysis initialization. The sediments from ODP 967 provide a challenge for unmixing analysis, because the sediment

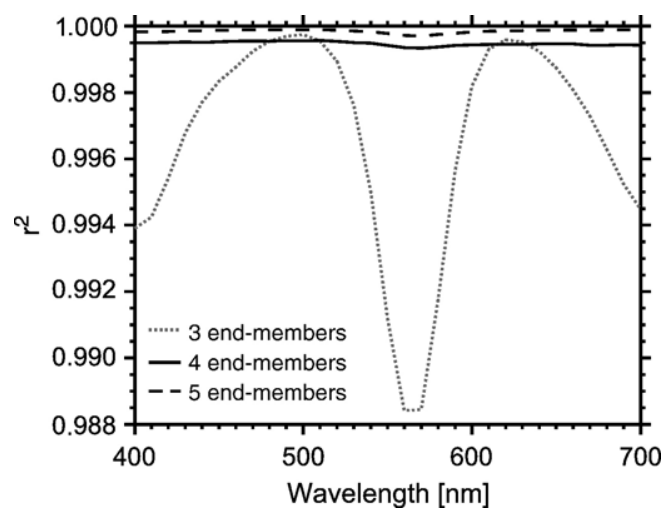

Fig. 4. Results of the model selection process applied to 3, 4 and 5 endmember solutions for the numerical experiment data set. Determination of $r^{2}$ for each spectral wavelength shows that a 3 end-member model cannot account for the data variance at a number of wavelengths. In contrast $r^{2}$ is $\sim 1$ for all wavelengths in the 4 endmember solution and the introduction of an extra end-member results in only a slight improvement in the model. 
matrix changes dramatically between the sapropel and marl layers. In earlier work concerned with the quantification of iron oxide content using DRS measurements Deaton and Balsam (1991) showed that a darker organic rich matrix would suppress the iron oxide signal and result in its content being underestimated. Alternatively, the signal of iron oxides residing in a brighter carbonate rich matrix would be promoted leading to an overestimation of the abundance. Such effects are not surprising, as light passes through a sediment it will interact with more than one mineral as it undergoes multiple scattering events. The manner of the interaction between the different mineral components which produces the final reflectance is non-linear and is responsible for the effect observed experimentally by Deaton and Balsam (1991) and earlier studies (Nash and Conel, 1974). Although, methods are available to compensate for these non-linear effects a detailed knowledge of sample mineralology and grain size is required before unmixing can be performed (Hapke, 1993), therefore for cases such as the ODP Site 967 sediments a linear unmixing must be adopted. We will show that whilst the matrix may have non-linear effects on the DRS measurement it is still possible to obtain an interpretable result from a linear model.

Examination of the spectra produced by NMF and factor analysis indicated that a 4 end-member solution was appropriate to model the data, Fig. 5, and this was confirmed by the coefficient of determination versus wavelength plot from the NMF unmixing. The results of the NMF analysis in terms of the fractional abundance of the individual end-member components are shown in Fig. 6 and the results from the factor analysis are shown as scores in Fig. 7.
The reflectance of the NMF derived end-member spectra and the form of their first derivative curves provide a clear interpretation of the dominant materials contributing to the reflectance of the 967A sediments, Fig. 5. It is a relatively simple task to identify the endmember corresponding to organic matter (solid black line), which is by far the darkest end-member and has maximum fractional abundances coincident with the recorded positions of the sapropels, Fig. 6. It is important to note that based on the DRS data the fractional abundances of organic material can be as high as 0.9 in the sapropel layers, however the real concentration is known to be much lower (Emeis and Sakamoto, 1998). This overrepresentation of the organic components is due to the non-linear matrix effects discussed above. As mentioned previously the NMF fractional abundances must be considered as a measure of the various contributions to sediment reflectance and not the mass composition of the sample.

The aeolian end-member (Fig. 5, black short dashed line) can be identified from its derivative curve and appears to predominantly consist of hematite and goethite. To confirm this hypothesis reference spectra for hematite and goethite were mixed together numerically in a linear manner corresponding to a ratio of $1: 2$, Fig. 8. A close correspondence between the end-member spectrum obtained from the 967 data set and the hematite and goethite mixture supports the conclusion that this component represents aeolian material transported to the site location from the surrounding desert regions. The fractional abundance of the aeolian end-member is consistently low in the sapropel layers and increasing to maxima in the intercalated marls. The potential importance of such an end-member is demonstrated by

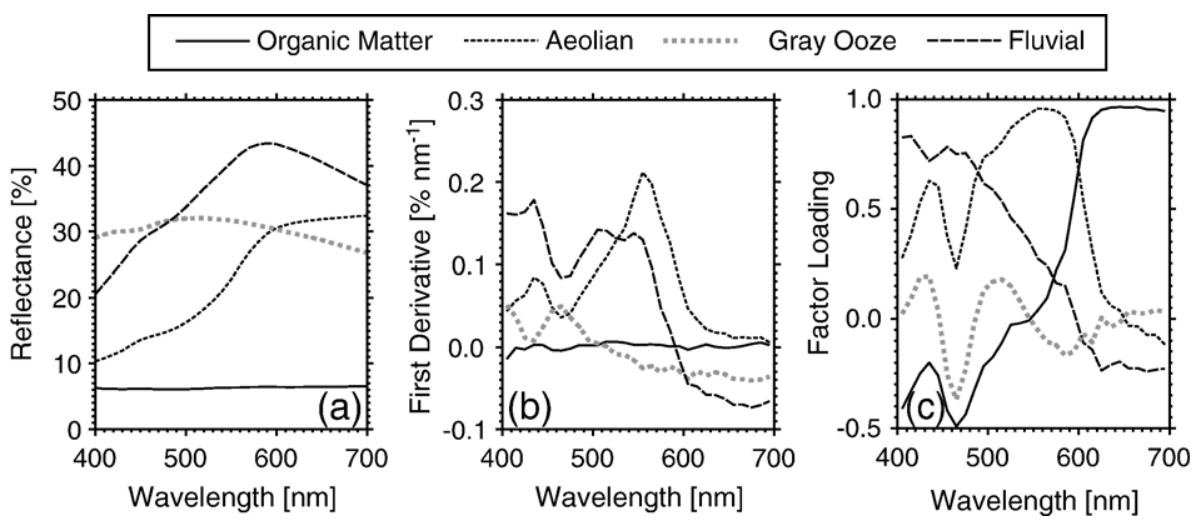

Fig. 5. End-member spectra and factors calculated for the ODP 967A data set. (a) The end-members extracted from the percentage reflectance spectra using NMF can be converted into the first derivative curves, which are shown in (b). The spectra shown in (c) are loadings obtained by factor analysis with a Varimax rotation performed on the first derivative curves of the measured spectra. A discussion of the assignment of specific sediment constituents to the calculated end-members is given in the text. 


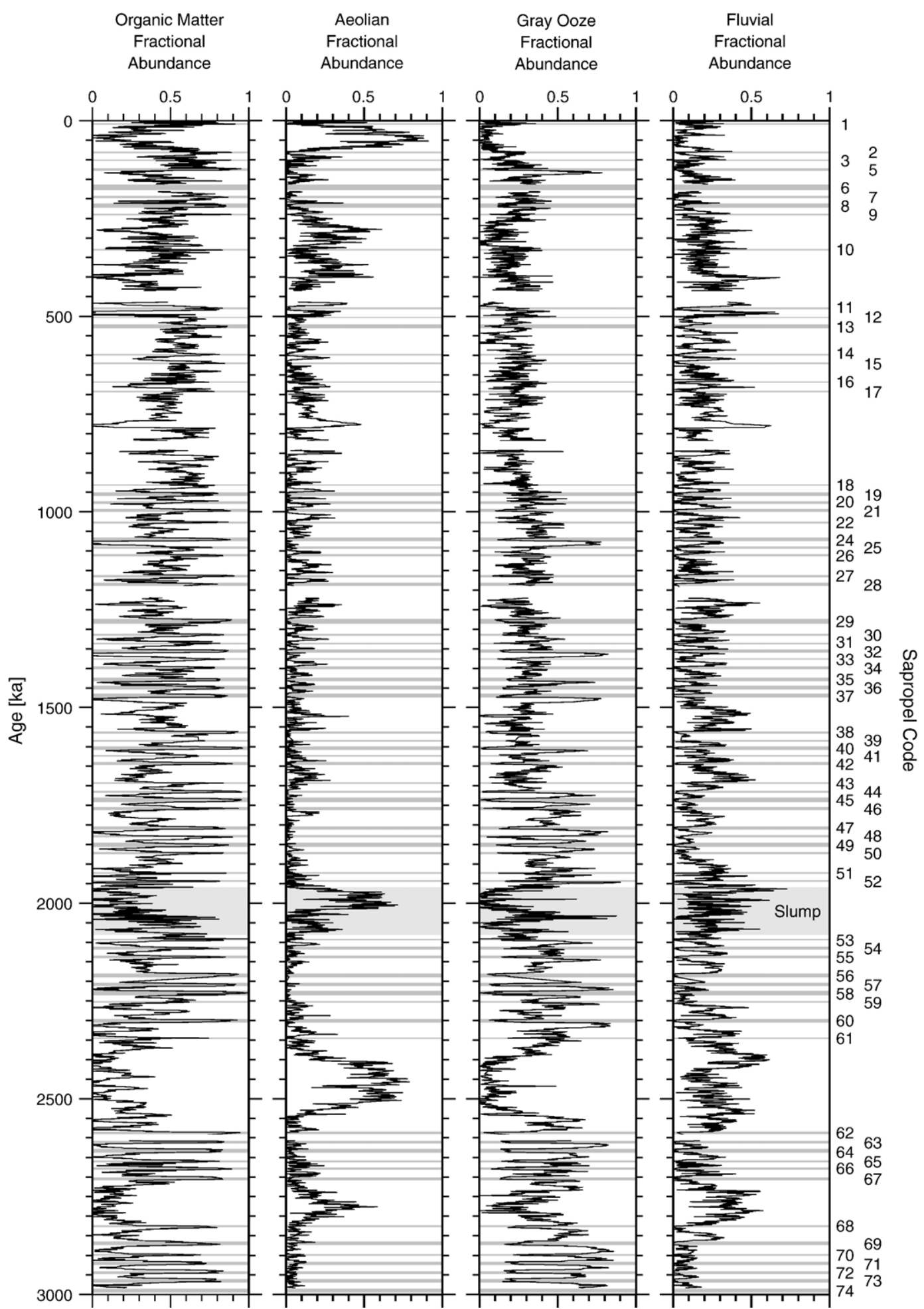

Fig. 6. Calculated fractional abundances for the NMF end-member spectra of ODP 967A shown in Fig. 5(a). The locations of sapropels in the sediment sequence are marked with gray bars and assigned codes according to the chronology of Kroon et al. (1998). 

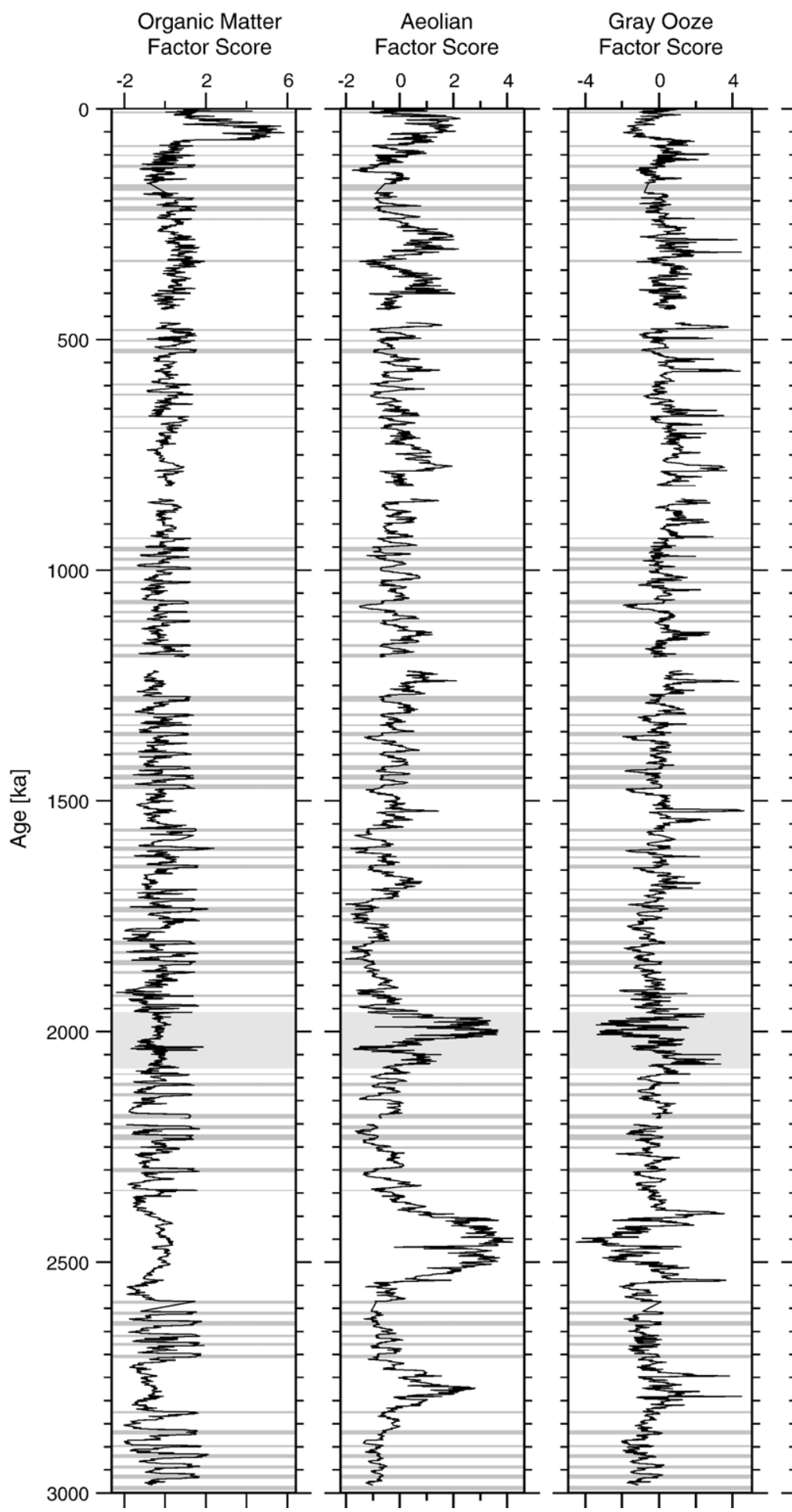

Fluvial

Factor Score

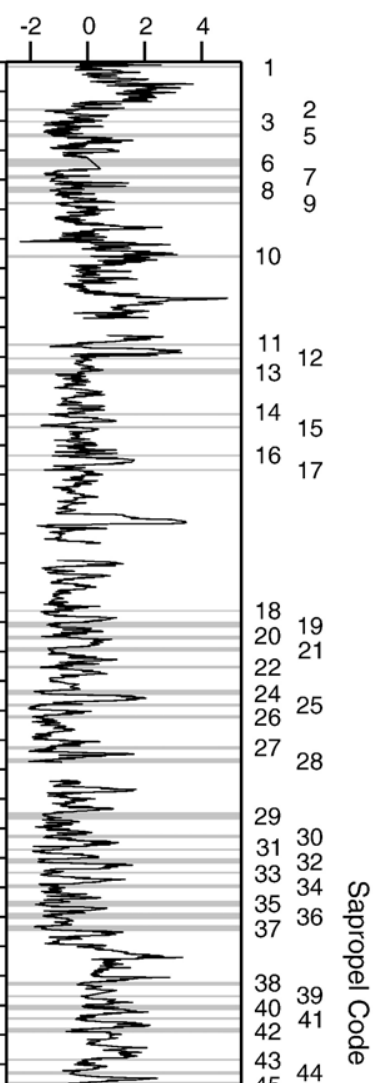

Fig. 7. Scores for factor loading spectra of ODP 967A shown in Fig. 5(c). The locations of sapropels in the sediment sequence are marked with gray bars and assigned codes according to the chronology of Kroon et al. (1998). It is important to note that unlike NMF where the abundances are always non-negative, the factor scores take both positive and negative values. 

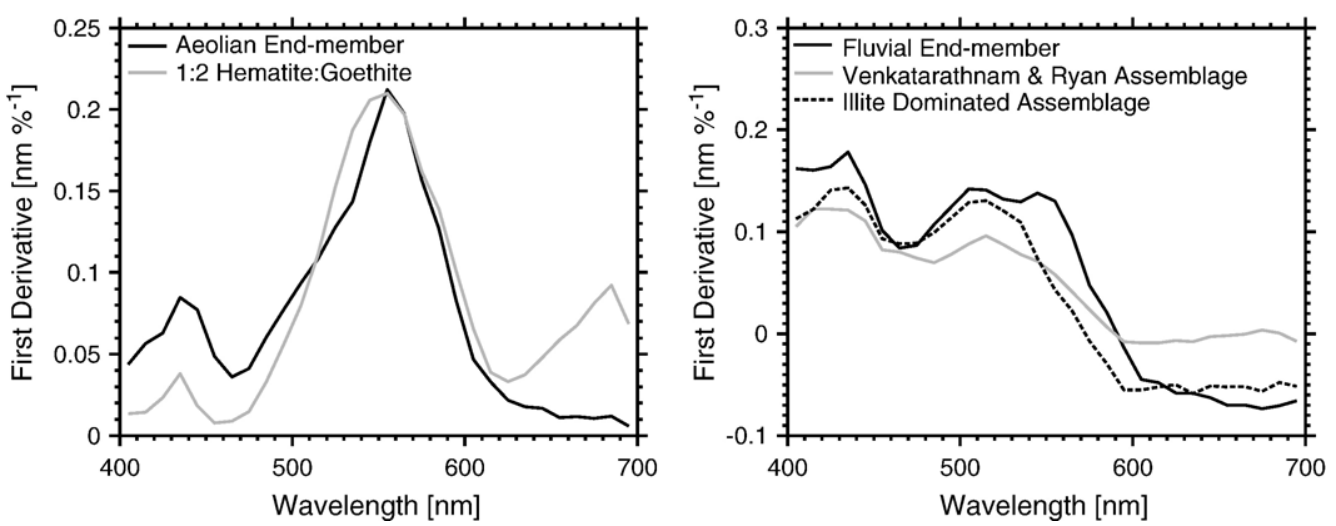

Fig. 8. Comparison of the NMF recovered end-members of ODP 967A to numerical mixtures of spectra obtained from reference materials. In the left panel the end-member (black line) contains a number of similarities in its structure to a 1:2 mixture of hematite and goethite (gray line), indicating that the end-member corresponds to the aeolian dust component. In the right panel a more complex situation is shown comparing the brightest endmember (black line) to the spectrum expected for the Nile clay mineral assemblage (gray line) quantified by Venkatarathnam and Ryan (1971). Whilst there is a good correspondence between these two curves the quality of the fit can be improved if the illite contribution is increased (dashed line).

sediment trap studies in the eastern Mediterranean, which have shown that the major component of the modern mass flux is likely to be Saharan dust (Rutten et al., 2000).

The remaining two end-members are more difficult to identify. A large volume of suspended material transported by the Nile is expected to reach the location of Site 967. The clay composition of such a contribution has be determined previously and is expected to consist of approximately $55 \%$ smectite, $25 \%$ kaolinite and $10 \%$ of both illite and chlorite (Venkatarathnam and Ryan, 1971). Reference spectra for these minerals were obtain from the USGS Digital Spectral Library splib05a (Clark et al., 2003) and mixed numerically in the abundances specified by Venkatarathnam and Ryan (1971). The first derivative of the resulting spectrum shares a number of features with the brightest end-member produced by the NMF unmixing, Fig. 8. It was found that an improved fit with the NMF end-member could be achieved if the fractional abundance of illite was increased, this may be due to the fact that illite appears to have a disproportionately high effect on the reflectance of sediments as reported previously by Balsam et al. (1999). The final end-member (Fig. 5, dashed thick gray line) is the hardest to identify, however, by a process of elimination it is apparent that it corresponds to the gray nannofossil ooze found in the hemipelagic marl layers that separate the sapropels. This interpretation is supported by the flat shape of the spectrum and the end-member abundance reaches maxima in marl layers and minima in the sapropels.

The fractional abundances calculated by the NMF algorithm are constrained to sum to 1 and as such represent a "closed" data array. Therefore the fractional abundances are not independent and any relationships that exist between the end-members must be considered in such a context. The effect of the closed data is seen in the sapropel layers and serves as a good example in understanding variations in the fractional abundances. During minima in precession raised humidity levels result in an increased Nile discharge. In addition, changes in circulation patterns and high nutrient content lead to eutrophic conditions and the formation of sapropel layers in the eastern Mediterranean. Given such a palaeoenvironmental scenario it would be expected that the abundance of the fluvial assemblage end-member would increase in sapropels, instead the reverse situation is seen with the fractional abundance decreasing to a local minimum. This effect is due to the proportionally greater increase in the organic matter component forcing the fractional abundance of the fluvial assemblage to lower values. In contrast, when Nile discharge increases during precession minima but conditions are not conducive to sapropel formation the fractional abundance of the fluvial component will be greater. It is important to note that reflectance data are inherently closed by nature and not as a result of the NMF processing technique. Therefore although fractional abundances may prove difficult to interpret they are the only way in which the unmixed reflectance data can be represented properly.

The form of end-member spectra based on the loadings of the factor analysis show some similarities to the derivative curves obtained by NMF but they are more difficult to assign to specific sources, Fig. 5(c). Because factor analysis does not provide percentage reflectance values it is not easy to know if an end- 
member represents a dark or light material. For example, whilst the aeolian factor can be recognized because of its characteristic hematite and goethite peaks, it is more difficult to identify the organic matter factor without percentage reflectance information. Based on the shape of the loading curves and the variations of scores with respect to the sediment lithology the four extracted factors have been assigned to the same sources as the NMF end-member spectra.

To test the consistency of the NMF and factor analysis approaches, a method termed Orbital Cycle Stacking is introduced. Segments in each time series which represent a single precession cycle bounded by an upper and lower sapropel layer were selected. It was assumed that in terms of angles the duration of each segment was equal to $2 \pi$ radians. Once linearly interpolated from the time domain onto an angular scale the individual data segments were detrended in order that the values at 0 and $2 \pi$ were identical, before being stacked together, Fig. 9. The concept behind this approach is that the waveforms of the individual end-members are expected to be consistent between cycles and orbital cycle stacking will reveal this behaviour. Thus orbital cycle stacking provides information concerning the average cycle shape of the different end-member fractional abundances and will yield insights into the relationships that exist between them. In cases where the behaviour is inconsistent between cycles the stacking procedure should average out to show a shape with no coherent waveform.

For the NMF approach the orbital cycle stacking must produce forms that still conform to the sum-to-one constraint. The organic matter has a maximum in the lower sapropel layer, gradually decreases to a minimum in the marl, before increasing to a second maximum in the overlying sapropel. The three other end-members vary in the opposite sense, showing minima in the sapropels and maxima in the marl. The waveforms for the different end-members are strongly correlated to each other, this represents the variation of the palaeoclimatic and palaeoceanographic changes in the Mediterranean over the last $3 \mathrm{Myr}$, but also reflects the closed nature of reflectance data. The orbital cycle stacking result for the factor scores is more difficult to interpret and a number of contradictory points appear. For example, the factor scores for the gray ooze component decrease in the marl layer where they would be expected to increase. The aeolian scores are negative throughout the cycle and it is therefore not clear if such behaviour is due to standardization of the score values during the factor analysis or the requirement of subtractive relationships to explain the first derivative data in terms of factors.

The fractional abundance of the aeolian end-member produced by the NMF analysis is of particular interest because it can be compared to other proxies of dust input into the Mediterranean. Based on hematite content derived from the magnetic properties of the ODP Site 967 sediments, Larrasoana et al. (2003) produced a record of dust supply into the eastern Mediterranean for the last 3 Myr. Thermal demagnetization of isothermal remanent magnetization led Larrasoana et al. (2003) to conclude the that aeolian dust reaching the location of Site 967 was hematite rich with a low goethite content.
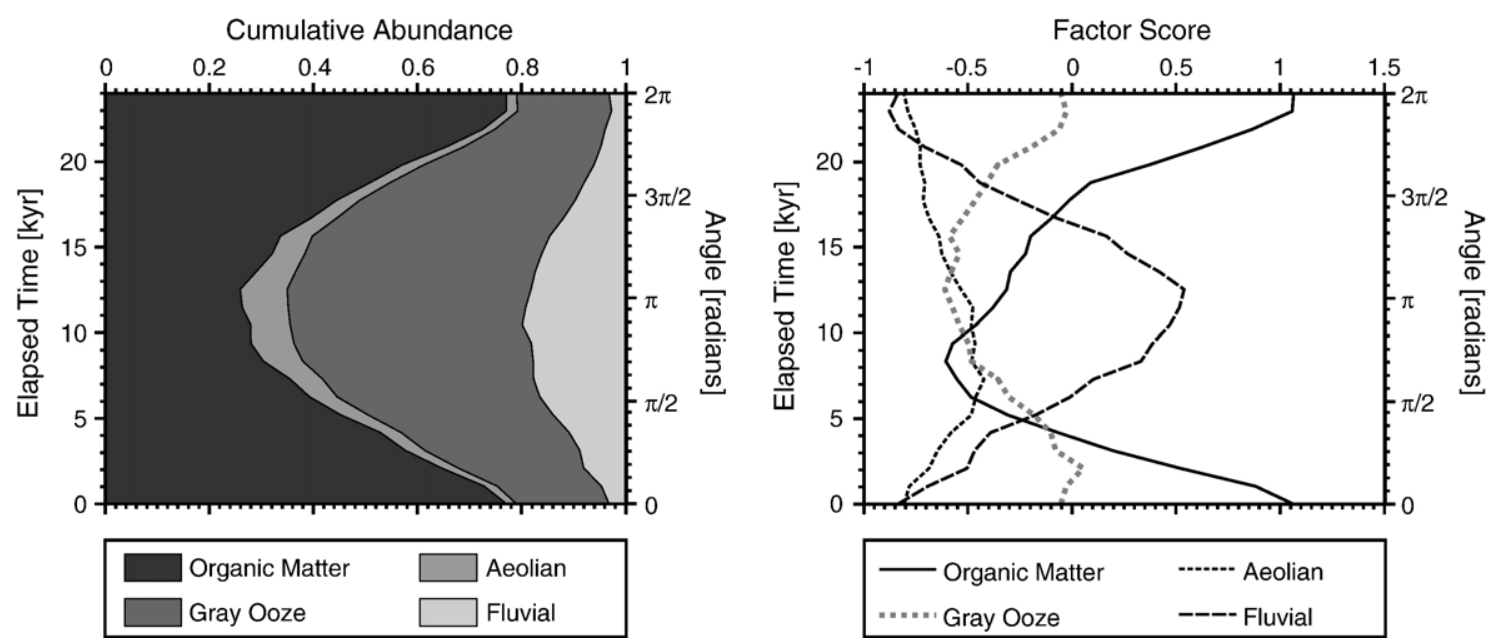

Fig. 9. Orbital cycle stacking of the NMF fractional abundance and factor analysis scores. In this representation a sapropel is positioned at 0 and the overlying sapropel, separated by one precession cycle, is positioned at an angle of $2 \pi$ and elapsed time of 24 kyr. The fractional abundances are still non-negative and meet a sum-to-one constraint, revealing a clear structure during the cycle. From left to right the different shadings of the cumulative abundance represent organic matter, aeolian, gray ooze and fluvial components. In contrast the factor scores do not show such coherent waveforms, see text for explanation. 
This is in contrast to the NMF unmixing which revealed a strong goethite contribution in the aeolian endmember. The source of the disparity may lie in the experimental procedure of Larrasoana et al. (2003) who magnetized their sediments in a maximum field of $900 \mathrm{mT}$. The coercivity of remanence for goethite is typically $>2 \mathrm{~T}$ (Peters and Dekkers, 2003) and therefore the vast majority of goethite particles would not have been magnetized by the fields applied by Larrasoana et al. (2003). This suggests that the goethite component of the aeolian dust was effectively invisible to the employed magnetic procedure.

Setting the question of specific dust composition aside, the IRM@AF parameter of Larrasoana et al. (2003) follows the Ti/Al ratio for the 967 sediments closely and provides a high resolution record of dust transport that can be compared to the fractional abundance of the aeolian end-member. The IRM@AF parameter was measured on the ODP Site 967 sediments at a resolution of $1 \mathrm{~cm}$ (Larrasoana et al., 2003), however, the narrow-access long-core cryogenic magnetometer employed in the investigation does not perform spot measurements but instead measures an integrated signal across part of the core. Roberts (2006) reports the response function of the magnetometer used by Larrasoana et al. (2003) to be approximately Gaussian in shape with a half-power width of $\sim 5 \mathrm{~cm}$. Such a function will produce some spatial smoothing in the measured data, therefore the NMF fractional abundance values were mathematically convolved with a similar function (a Gaussian probability density function with a standard deviation of $2.12 \mathrm{~cm}$ ) to aid the comparison of the records, Fig. 10.

Whilst both the aeolian end-member and the IRM@AF parameter show basically the same cycles there are also clear disparities in the relative peak sizes associated with the various events. This behaviour can in part be related to the closed reflectance data where variation in the aeolian fractional abundance is also controlled by the abundances of the other end-members. To examine the relationship between reflectance and IRM@AF more closely the section of the records between 900 and $1500 \mathrm{kyr}$ was selected because of the large number of sapropels occurring across that period. The fractional abundance data of all four end-members are shown in Fig. 11 in addition to the log-ratio of the aeolian and sapropel components. The alternating pattern of sapropel and marl layers is represented strongly in the

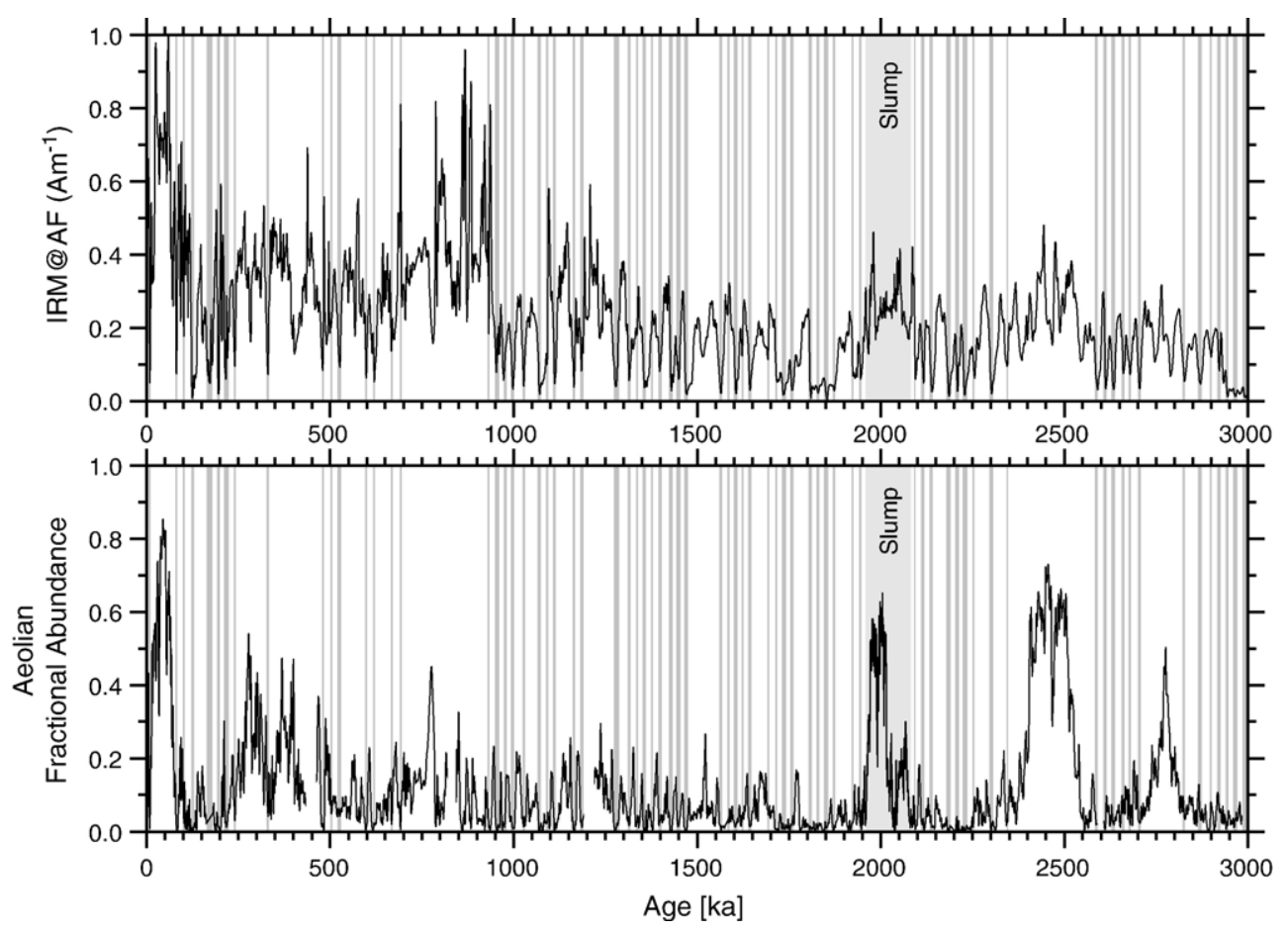

Fig. 10. Comparison of the dust proxy parameter IRM@AF reported by Larrasoana et al. (2003) and the fractional abundance of the aeolian component recovered by NMF. The locations of sapropels in the sediment sequence are marked with gray bars according to the chronology of Kroon et al. (1998). Both parameters show increased (decreased) values in the marl (sapropel) layers but there are also some important differences in the curves due to the closed nature of the DRS data set. 


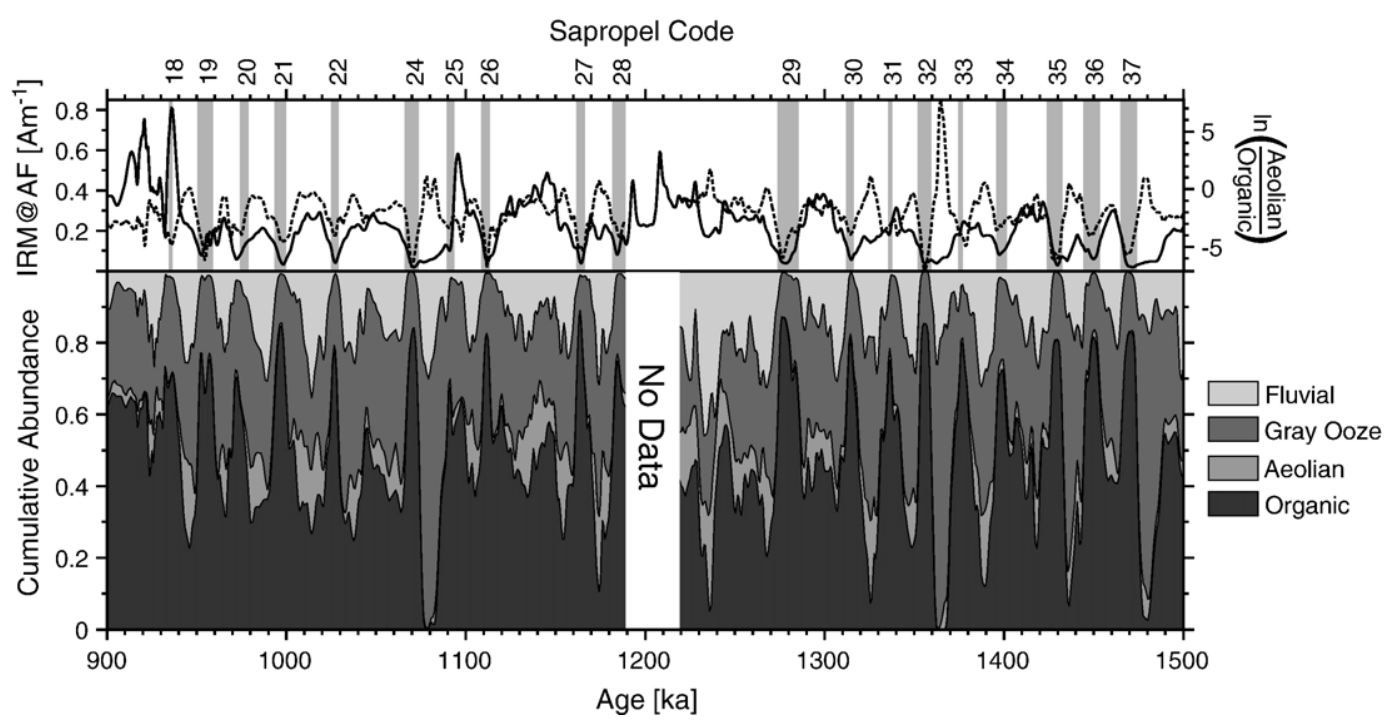

Fig. 11. When shown as cumulative abundances for the period 900-1500 ka, the complexity of the full fractional abundance data becomes apparent. The log-ratio of the aeolian and organic end-members is shown in the top panel (dashed line) in an attempt to compare fractional abundance information with the IRM@AF curve (top panel, black line) of Larrasoana et al. (2003).

cumulative abundance data, however, the relationship between the four end-members is complex, demonstrating that simply plotting the fractional abundance of a single component could be misleading. Log-ratios were proposed by Aitchison (1986) as a more robust method of handling closed data sets. The presented ratio shows a good correspondence to the IRM@AF parameter, with clear alternation between the sapropels and marls. At some points, for example when the abundance of organic matter is very low at an age of $1365 \mathrm{ka}$, the relationship between the records breaks down and a peak is observed in the log-ratio curve.

\section{Conclusions}

Previous studies have demonstrated that DRS provides a rapid method for mapping variations in the constituents of marine sediments across both space and time. The applicability of linear unmixing in the decomposition of DRS data sets has been shown with factor analysis, but as discussed, such an approach has a number of problems.

Numerical experiments and a case-study from the Mediterranean have demonstrated the suitability of NMF to the problem of unmixing DRS data. The NMF algorithm can be applied to measured data sets to solve for a predefined number of end-members, finding both their fractional abundances and percentage reflectance spectra. Most importantly, the NMF approach yields sum-to-one fractional abundances that are con- strained to be non-negative and thus, unlike factor analysis, only additive relationships are permitted.

The new technique of orbital cycle stacking applied to the ODP Site 967 data reveals that NMF gives consistent results from cycle to cycle, showing the kind of variation that would be expected in the orbital scale environmental change of the Mediterranean.

One limitation of DRS unmixing using both factor analysis and NMF is the ability to relate the determined end-member spectra to real sediment constituents. Although databases exist which contain reference spectra for a large number of materials it can be difficult to unequivocally identify end-members which are a mixture of a number of different minerals. It is therefore advantageous to have information from alternative analysis techniques that can be used to identify possible candidate minerals which could be associated to the NMF end-members.

As DRS is a standard logging measurement on many research cruises it is important to have a robust data processing methodology to help quantify sediment composition. NMF provides a suitable processing method that can be applied rapidly to large numbers of spectra and which meets the natural constraints of such DRS data sets.

\section{Acknowledgements}

Two anonymous reviewers are thanked for their critical comments. We are also grateful to J.C. Larrasoana who provided magnetic data from ODP Site 967. This work was 
supported by the German Science foundation (DFG) as part of the Research Center Ocean Margins (contribution RCOM0488) and the International Graduate College Proxies in Earth History, University of Bremen.

\section{References}

Aitchison, J., 1986. The Statistical Analysis of Compositional Data. Chapman and Hall, London.

Balsam, W.L., Deaton, B.C., 1991. Sediment dispersal in the Atlantic Ocean: evaluation by visible light spectra. Rev. Aquat. Sci. 4, 411-447.

Balsam, W.L., Wolhart, R., 1993. Sediment dispersal in the Argentine Basin: evidence from visible light spectra. Deep-Sea Res. II 40, 1001-1031.

Balsam, W.L., Deaton, B.C., 1996. Determining the composition of late Quaternary marine sediments from NUV, VIS and NIR diffuse reflectance spectra. Mar. Geol. 134, 31-55.

Balsam, W.L., Damuth, J.E., 2000. Further investigations of shipboard vs. shore-based spectral data: implications for interpreting Leg 164 sediment composition. In: Paull, C.K., Matsumoto, R., Wallace, P.J., Dillon, W.P. (Eds.), Proc. ODP Sci. Res., vol. 164, pp. 313-324.

Balsam, W.L., Beeson, J.P., 2003. Sea-floor sediment distribution in the Gulf of Mexico. Deep-Sea Res. I 50, 1421-1444.

Balsam, W.L., Otto-Bliesner, B.L., Deaton, B.C., 1995. Modern and last glacial maximum eolian sedimentation patterns in the Atlantic Ocean interpreted from sediment iron oxide content. Paleoceanography 10 (3), 493-507.

Balsam, W.L., Damuth, J.E., Schneider, R.R., 1997. Comparision of ship-board vs. shore-based spectral data from Amazon fan cores: implications for interpreting sediment composition. In: Flood, R., Piper, D.J.W., Klaus, A., Peterson, L.C. (Eds.), Proc. ODP Sci. Res., vol. 155, pp. 193-215.

Balsam, W.L., Deaton, B.C., Damuth, J.E., 1999. Evaluating optical lightness as a proxy for carbonate content in marine sediment cores. Mar. Geol. 161, 141-153.

Barranco Jr., F.T., Balsam, W.L., Deaton, B.C., 1989. Quantitative reassessment of brick red lutites: evidence from reflectance spectrophotometry. Mar. Geol. 89, 299-314.

Burnham, K.P., Anderson, D.R., 2002. Model Selection and Multimodel Inference: A Practical Information-Theoretic Approach. Springer-Verlag Inc., Berlin.

Clark, R., Swayze, G., Wise, R., Livo, K., Hoefen, T., Kokaly, R., Sutley, S., 2003. USGS Digital Spectral Library splib05a. U.S. Geological Survey, Open File Report 03-395.

Damuth, J.E., Balsam, W.L., 2003. Data report: spectral data from Sites 1165 and 1167 including the HiRISC section from Hole 1165B. In: Cooper, A.K., O’Brien, P.E., Richter, C. (Eds.), Proc. ODP Sci. Res., vol. 188, pp. 1-49.

Davis, J.C., 1986. Statistics and Data Analysis in Geology, 2nd Edition. John Wiley \& Sons, Inc., New York.

Deaton, B.C., Balsam, W.L., 1991. Visible spectroscopy — a rapid method for determining hematite and goethite concentration in geological materials. J. Sediment. Petrol. 61, 628-632.

Du, Q., Kopriva, I., Szu, H., 2005. Investigation on constrained matrix factorization for hyperspectral image analysis. Geoscience and Remote Sensing Symposium, 2005. IGARSS '05. Proceedings. 2005. IEEE International, vol. 6, pp. 4304-4306.

Emeis, K.-C., Sakamoto, T., 1998. The sapropel theme of Leg 160. In: Robertson, A.H.F., Emeis, K.-C., Richter, C., Camerlenghi, A. (Eds.), Proc. ODP Sci. Res., vol. 160, pp. 29-36.
Giosan, L., Flood, R.D., Aller, R.C., 2002. Paleoceanographic significance of sediment color on western North Atlantic drifts: I. Origin of color. Mar. Geol. 189, 25-41.

Hapke, B., 1993. Theory of Reflectance and Emittance Spectroscopy. Cambridge University Press, Cambridge, U.K.

Holz, C., Stuut, J.B.W., Henrich, R., 2004. Terrigenous sedimentation processes along the continental margin off NW Africa: implications from grain-size analysis of seabed sediments. Sedimentology 51 (5), $1145-1154$.

Jin, L., Ji, J., Balsam, W., Chen, Y., Chen, J., Lu, H., 2003. Determining magnetic susceptibility in loess-paleosol sections by near-infrared reflectance spectroscopy. Geophys. Res. Lett. 30 (10). doi:10.1029/ 2003/GL017389.

Keshava, N., Mustard, J., 2002. Spectral unmixing. IEEE Signal Process. Mag. 19 (1), 44-57.

Keshava, N., Kerekes, J., Manolakis, D., Shaw, G., 2000. An algorithm taxonomy for hyperspectral unmixing. Proc. of the SPIE AeroSense Conference on Algorithms for Multispectral and Hyperspectral Imagery VI, vol. 4049, pp. 42-63.

Kroon, D., Alexander, I., Little, M., Lourens, L.J., Matthewson, A., Robertson, A.H.F., Sakamoto, T., 1998. Oxygen isotope and sapropel stratigraphy in the Eastern Mediterranean during the last 3.2 million years. In: Robertson, A.H.F., Emeis, K.-C., Richter, C., Camerlenghi, A. (Eds.), Proc. ODP Sci. Res., vol. 160, pp. 181-190.

Langville, A.N., Meyer, C.D., Albright, R., 2006. Initializations for the non-negative matrix factorization. Proceedings of the Twelfth ACM SIGKDD International Conference on Knowledge Discovery and Data Mining.

Larrasoana, J.C., Roberts, A.P., Rohling, E.J., Winklhofer, M., Wehausen, R., 2003. Three million years of monsoon variability over the northern Sahara. Clim. Dyn. 21, 689-698.

Lee, D.D., Seung, H.S., 1999. Learning the parts of objects by nonnegative matrix factorization. Nature 401, 788-791.

Lee, D.D., Seung, H.S., 2001. Algorithms for non-negative matrix factorization. Adv. Neural Inf. Process. Syst. 13, 556-562.

Lourens, L.J., Antonarakou, A., Hilgen, F.J., van Hoof, A.A.M., Vergnaud-Grazzini, C., Zachariasse, W.J., 1996. Evaluation of the Plio-Pleistocene astronomical timescale. Paleoceanography 11 (4), 391-413.

Lourens, L.J., Wehausen, R., Brumsack, H.J., 2001. Geological constraints on tidal dissipation and dynamical ellipticity of the Earth over the past three million years. Nature 409, 1029-1033.

Mix, A.C., Harris, S.E., Janecek, T.R., 1995. Estimating lithology from nonintrusive reflectance spectra: Leg 138. In: Pisias, N.G., Mayer, L.A., Janecek, T.R., Palmer-Julson, A., van Andel, T.H. (Eds.), Proc. ODP Sci. Res., vol. 138, pp. 413-427.

Nash, D., Conel, J., 1974. Spectral reflectance systematics for mixtures of powdered hypersthene, labradorite and ilmenite. J. Geophys. Res. 79, 1615-1621.

Ortiz, J., Mix, A., Harris, S., O’Connell, S., 1999a. Diffuse spectral reflectance as a proxy for percent carbonate content in North Atlantic sediments. Paleoceanography 14 (2), 171-185.

Ortiz, J.D., O`Connell, S., Mix, A., 1999b. Data report: spectral reflectance observations from recovered sediments. In: Raymo, M.E., Jansen, E., Blum, P., Herbert, T.D. (Eds.), Proc. ODP Sci. Res., vol. 162, pp. 259-264.

Peters, C., Dekkers, M., 2003. Selected room temperature magnetic parameters as a function of mineralogy, concentration and grain size. Phys. Chem. Earth 28, 659-667.

Peterson, L.C., Haig, G.H., Hughen, K.A., Röhl, U., 2000. Rapid changes in the hydrologic cycle of the tropical Atlantic during the Last Glacial. Science 290, 1947-1951. 
Roberts, A., 2006. High-resolution magnetic analysis of sediment cores: strengths, limitations and strategies for maximizing the value of long-core magnetic data. Phys. Earth Planet. Inter. 156, $162-178$

Rutten, A., de Lange, G., Ziveri, P., Thomson, J., van Santvoort, P., Colley, S., Corselli, C., 2000. Recent terrestrial and carbonate fluxes in the pelagic eastern Mediterranean; a comparison between sediment trap and surface sediment. Palaeogeogr. Palaeoclimatol. Palaeoecol. 158, 197-213.

Sakamoto, T., Emeis, K.-C., 1998. Continuous sedimentary sequences from the Eastern Mediterranean Sea: composite depth sections. In: Robertson, A.H.F., Emeis, K.-C., Richter, C., Camerlenghi, A. (Eds.), Proc. ODP Sci. Res., vol. 160, pp. 37-59.

Stuut, J.B.W., Prins, A.M., Schneider, R.R., Weltje, G.J., Jansen, J.H.F., Postma, G., 2002. A 300-kyr record of aridity and wind strength in southwestern Africa: inferences from grain-size distributions of sediments on Walvis Ridge, SE Atlantic. Mar. Geol. 180 (1-4), 221-233.

Venkatarathnam, K., Ryan, W.B.F., 1971. Dispersal patterns of clay minerals in the sediments of the eastern Mediterranean Sea. Mar. Geol. 11,, 261-282.

Wehausen, R., Brumsack, H.J., 1998. The formation of Pliocene Mediterranean sapropels: constraints from high-resolution major and minor element studies. In: Robertson, A.H.F., Emeis, K.-C., Richter, C., Camerlenghi, A. (Eds.), Proc. ODP Sci. Res., vol. 160, pp. 207-217.

Weltje, G.J., 1997. End-member modeling of compositional data: numerical-statistical algorithms for solving the explicit mixing problem. Math. Geol. 29, 503-549.

Wild, S., Curry, J., Dougherty, A., 2003. Motivating non-negative matrix factorizations. Proceedings of the Eighth SIAM Conference on Applied Linear Algebra. 